\title{
Product Placement im Fernsehen
}

Die Legalisierung programmintegrierter Werbung im Lichte der deutschen und europäischen Kommunikationsgrundrechte

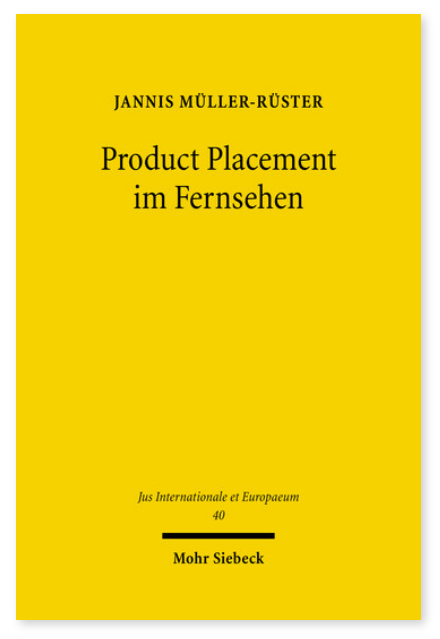

2010. XXI, 573 Seiten. JusIntEu 40

ISBN 978-3-16-151179-0

DOI 10.1628/978-3-16-151179-0

eBook PDF 119,00€

ISBN 978-3-16-150456-3

fadengeheftete Broschur 119,00€
Seit dem 1. April 2010 gelten neue Vorschriften für Product Placement im Fernsehen. Das bisherige Verbot der Schleichwerbung wurde vor allem im privaten Fernsehen erheblich gelockert und die entgeltliche Einbeziehung von Werbeobjekten in das Programm unter strengen Auflagen erlaubt. Mit der Legalisierung von »Produktplatzierung« im 13. Rundfunkänderungsstaatsvertrag setzen die Bundesländer die EU-Richtlinie über audiovisuelle Mediendienste in deutsches Recht um. Jannis Müller-Rüster unterzieht die umstrittenen Regelungen einer kritischen Analyse in Hinblick auf den Schutz der redaktionellen Unabhängigkeit und des Rezipientenvertrauens. Die verfassungsrechtlichen Implikationen des werberechtlichen Trennungsgrundsatzes werden eingehend untersucht und in den grundrechtsdogmatischen Kontext der Rundfunkfreiheit des Grundgesetzes sowie des europäischen Rechts eingeordnet.

Jannis Müller-Rüster Geboren 1980; Studium der Rechtswissenschaften in Berlin, Göttingen und Dijon; 2010 Promotion; Rechtsreferendar am Landgericht Hannover.

Jetzt bestellen:

https://mohrsiebeck.com/buch/product-placement-im-fernsehen-9783161511790?no_cache=1

order@mohrsiebeck.com

Telefon: +49 (0)7071-923-17

Telefax: +49(0)7071-51104 